\title{
L'église Saint-Pierre de Baume-les-Messieurs (Jura), troisième campagne
}

Marie-Laure Bassi, Sébastien Bully, Éliane Vergnolle et Laurent Fiocchi

\section{Q OpenEdition \\ 1 Journals}

Édition électronique

URL : https://journals.openedition.org/cem/11496

DOI : $10.4000 /$ cem. 11496

ISSN : 1954-3093

Éditeur

Centre d'études médiévales Saint-Germain d'Auxerre

Édition imprimée

Pagination : 19-22

ISSN : 1623-5770

Référence électronique

Marie-Laure Bassi, Sébastien Bully, Éliane Vergnolle et Laurent Fiocchi, «L'église Saint-Pierre de Baume-les-Messieurs (Jura), troisième campagne », Bulletin du centre d'études médiévales d'Auxerre BUCEMA [En ligne], 14 | 2010, mis en ligne le 15 octobre 2010, consulté le 22 septembre 2022. URL http://journals.openedition.org/cem/11496 ; DOI : https://doi.org/10.4000/cem.11496

Ce document a été généré automatiquement le 22 septembre 2022.

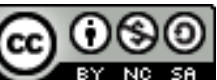

Creative Commons - Attribution - Pas d'Utilisation Commerciale - Partage dans les Mêmes Conditions 4.0 International - CC BY-NC-SA 4.0

https://creativecommons.org/licenses/by-nc-sa/4.0/ 


\title{
L'église Saint-Pierre de Baume-les- Messieurs (Jura), troisième campagne
}

\author{
Marie-Laure Bassi, Sébastien Bully, Éliane Vergnolle et Laurent Fiocchi
}

1 L'abbatiale de Baume-les-Messieurs a fait l'objet d'une programmation d'archéologie du bâti sur trois ans, dont la dernière campagne s'est déroulée au mois de février 2010. En tenant compte du travail et des observations déjà réalisés en 2007 et en 2008 sur le secteur du chevet ${ }^{1}$, la dernière campagne s'est orientée essentiellement sur le bas-côté sud.

2 L'intervention a porté principalement dans les combles du bas-côté sud, où l'on a observé d'intrigants désordres à la jonction du transept et du mur gouttereau du vaisseau central. On constate, en effet, la présence, sur deux travées, d'une maçonnerie plus large que ce dernier, qui disparaît ensuite dans les voûtes du bas-côté. Une coupe des combles a été réalisée et associée à la coupe transversale de l'église afin d'avoir une vision claire de cette maçonnerie prise dans le mur gouttereau du haut vaisseau. Une observation détaillée a montré que la maçonnerie est chainée avec le mur ouest du bras sud du transept, qui appartient à la première phase de construction de l'abbatiale identifiée lors des campagnes de 2007 et 2008. Il s'agirait donc là des vestiges de la première nef de l'église, qui aurait fonctionné avec le chevet à cinq chapelles échelonnées construit au début du XI ${ }^{\mathrm{e}}$ siècle. Malheureusement, les quelques assises de pierre conservées ne laissent pas envisager la longueur primitive de cette nef ni ses dispositions; seul un sondage archéologique dans la nef actuelle pourrait répondre à ces questions. 


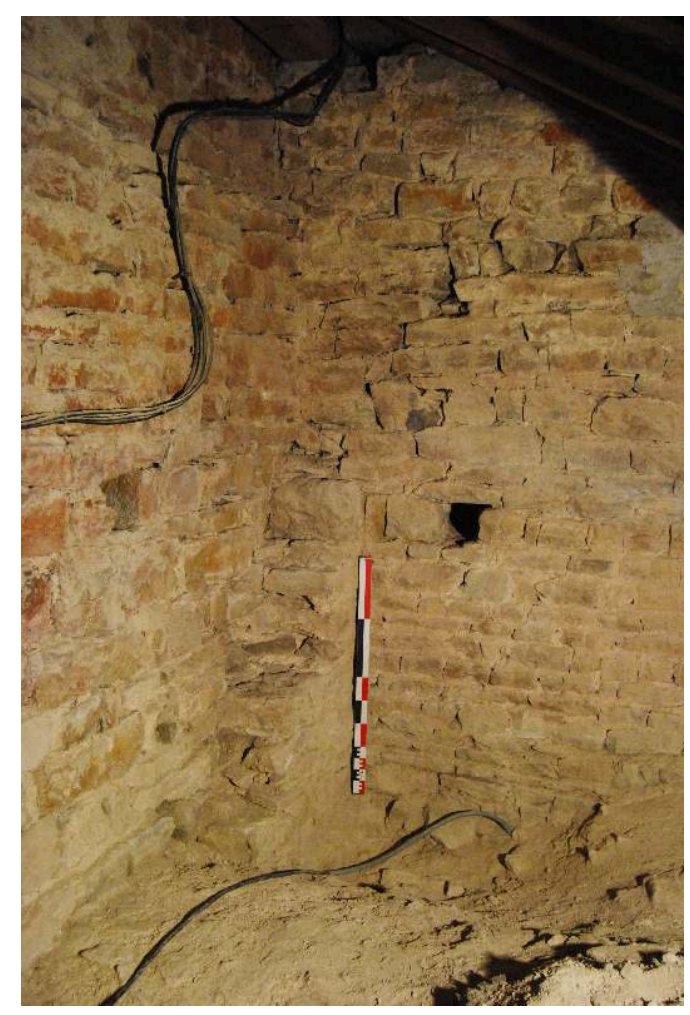

Fig. 1 - Baume-les-Messieurs, combles du bas-côté sud, détail de la maçonnerie de la première phase de la nef (cl. M.-L. Bassi)

3 À la suite, l'intégralité du parement sud du gouttereau sud du haut vaisseau a été relevée en pierre à pierre afin d'identifier des reprises dans les maçonneries. L'analyse de ce mur confrontée à la coupe longitudinale, réalisée lors de la première campagne en 2007, du parement intérieur permet de déterminer que l'ensemble de la nef actuelle a été réalisé en, au moins, deux phases de construction. 


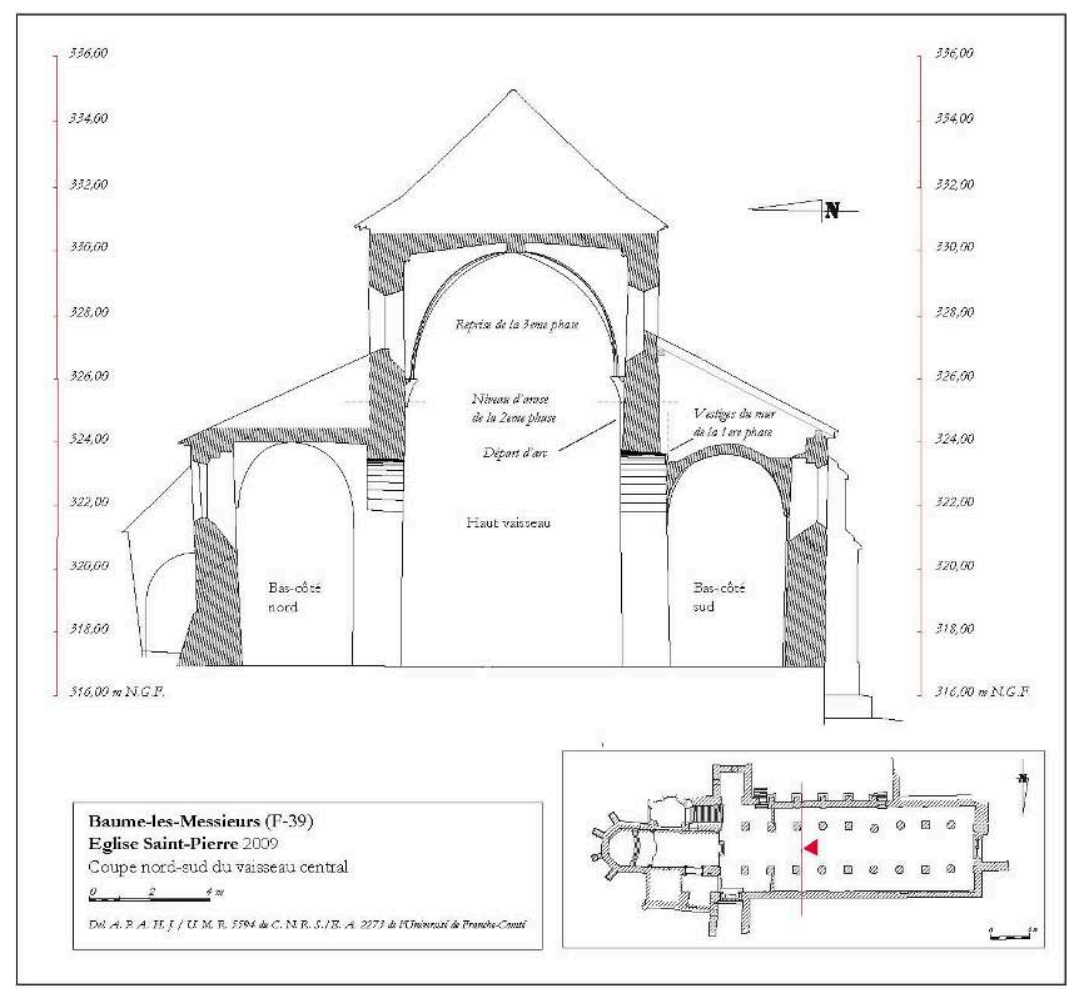

Fig. 2 - Baume-les-Messieurs, coupe nord-sud de la nef (L. Fiocchi, M.-L. Bassi).

Dans un premier temps, la construction aurait concerné les bas-côtés voûtés d'arêtes et les parties basses du haut vaisseau jusqu'à un niveau marqué à l'intérieur par l'arase d'arcs sous les baies hautes. Le niveau d'arase des arcs à l'intérieur correspond à un changement de maçonneries à la même cote altimétrique en parement extérieur sur toute la longueur de la nef. Nous pouvons donc avancer que le haut vaisseau a été détruit dans ses parties hautes très tôt, sans doute en raison de son mode de couvrement.

En effet, les vestiges d'arcs conservés dans le vaisseau central sont disposés toutes les deux travées et s'enfoncent dans le mur au-dessus des grandes arcades. On a longtemps cru qu'il s'agissait d'arcs diaphragmes liés à une charpente, mais c'est une découverte récente dans une autre église, qui se situe à environ vingt kilomètres de Baume-lesMessieurs, l'église Saint-Désiré de Lons-le-Saunier, qui nous éclaire sur leur fonction exacte $^{2}$. Ces mêmes arcs pénétrant dans les murs gouttereaux, et implantés aussi toutes les deux travées, fonctionnent avec le départ d'une voûte en berceau plein cintre. Il est donc aisé de comparer les deux édifices et de proposer le même mode de couvrement à Baume-les-Messieurs. Le vaisseau central aurait donc été voûté dès sa construction d'une voûte en berceau plein cintre, renforcée par des arcs doubleaux pénétrants disposés toutes les deux travées. Une différence notable existe pourtant entre les deux édifices puisqu'à Saint-Désiré de Lons-le-Saunier le vaisseau central est large de $5,80 \mathrm{~m}$, alors qu'à Baume-les-Messieurs le haut vaisseau présente une largeur de 7,20 m. C'est peut-être cette largeur importante qui explique que le voûtement a été vraisemblablement détruit assez rapidement, d'après ce que l'on observe dans les maçonneries. Les baies hautes actuelles, ainsi que la partie supérieure des gouttereaux du haut vaisseau qui les accueille, appartiennent donc à une troisième phase de construction romane, que l'on date approximativement entre la fin du $\mathrm{XI}^{\mathrm{e}}$ siècle et le 
début du XII ${ }^{e}$ siècle. Les voûtes d'ogives actuelles nous ont fait perdre tout indice sur le mode de couvrement qui fonctionnait avec ces baies, mais leurs dimensions importantes, ainsi que la largeur conséquente du vaisseau central associée à l'expérience de voûtement précédente, inviteraient à envisager un retour à la charpente.

Les résultats obtenus durant ces trois années ont entraîné une relecture radicale de l'abbatiale romane Saint-Pierre et confirment tout l'intérêt que représente une approche par l'archéologie du bâti de monuments longtemps étudiés à partir des seules études historiques et d'histoire de l'art. Les trois phases de construction romanes montrent que l'église a dû être un chantier permanent durant toute cette période. Alors que les études historiques suggéraient que l'abbaye ne prenait de l'ampleur qu'au milieu du XI ${ }^{e}$ siècle, le choix architectural du chevet à cinq chapelles échelonnées et deux tours de clocher sur les bras du transept reflètent un projet ambitieux dès l'an Mil.

7 L'expérience de voûtement sur le vaisseau central lors d'une deuxième campagne s'inscrit dans un courant de recherche précoce sur le voûtement que connut le Jura et plus largement la vallée de la Saône dans la première moitié du xie siècle. L'emploi d'une voûte en berceau plein cintre, renforcée de doubleaux pénétrant toutes les deux travées, montre une solution originale et innovante, mais qui n'aura guère de descendance ${ }^{3}$.

Désormais l'archéologie du sous-sol devrait prendre le relais pour préciser et enrichir ces découvertes. Une fouille de l'ensemble du chœur devrait être ouverte l'année prochaine et nous apporter des informations complémentaires qui enrichiront les connaissances sur le chevet roman, mais aussi sur les structures carolingiennes qui ont été repérées lors du sondage archéologique de février 2009.

\section{NOTES}

1. . M.-L. BAsSi, S. Bully, L. Fiocchi et É. Vergnolle, « L'église Saint-Pierre de Baume-les-Messieurs (Jura) », Bulletin du Centre d'études médiévales d'Auxerre, 12 (2008), p. 19-23 [http://cem.revues.org/ index6312.html]et Bulletin du Centre d'études médiévales d'Auxerre, 13 (2009), p. 47-52 [http:// cem.revues.org/index11207.html].

2. . M.-L. BASSI, "Saint-Désiré de Lons-le-Saunier", in Le "premier art roman " cent ans après. La construction entre Saône et Pô autour de l'an Mil, actes du colloque international de Baume-lesMessieurs et Saint-Claude, 18-21 juin 2009 (à paraître).

3. . À notre connaissance, ce dispositif de voûtement n'est conservé que pour ces deux églises. 
INDEX

Mots-clés : église

Index géographique : France/Baume-les-Messieurs 